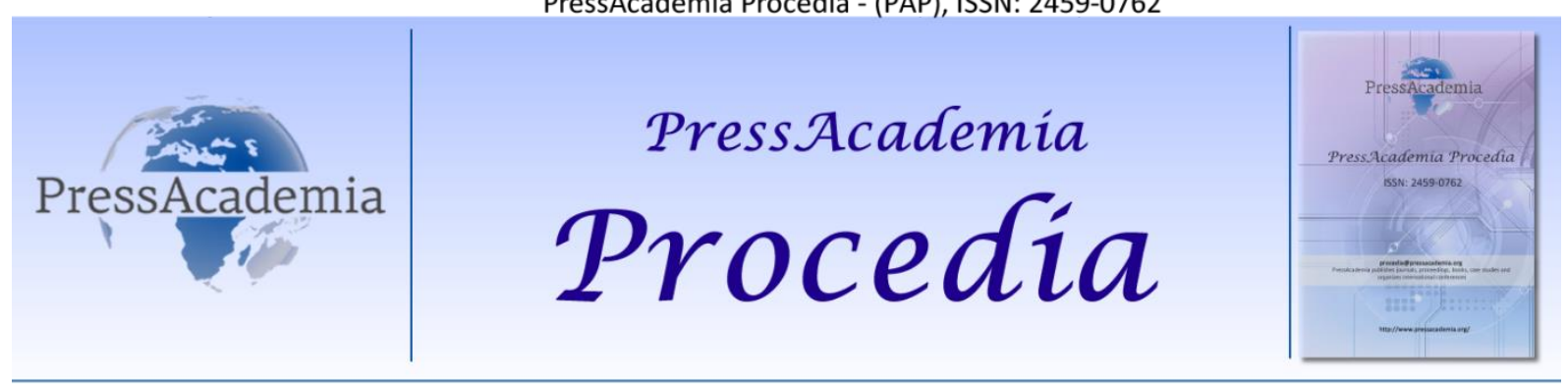

2nd World Conference on Technology, Innovation and Entrepreneurshi

May 12-14, 2017, Istanbul, Turkey. Edited by Sefer Şener

\title{
REGARDING THE QUALITY ORIENTED DEVELOPMENT AND AN OVERVIEW OF SUSTAINABILITY OF THIS APPROACH FOR INDUSTRIAL/SERVICE SECTORS: A CASE STUDY FOR SUPPLY CHAIN AND PRODUCTION SYSTEM OF XB FIRM
}

DOI: 10.17261/Pressacademia.2017.579

PAP-WCTIE-V.5-2017(17)-p.111-123

\author{
Ayşenur Erdil ${ }^{1}$, Mehtap Erdil ${ }^{2}$ \\ ${ }^{1}$ Marmara-Yalova University, erdil.aysenur@gmail.com \\ ${ }^{2}$ Istanbul University, erdilmehtap@gmail.com
}

\begin{abstract}
Six sigma provides to reduce cost by improving productivity and this method achieves this by focusing on the reduction of both defects and non-value added facilities. This method aims to reach zero defect in the theory improving supply chain processes. For extending and improving the effectiveness of supply chains, the critical processes of these systems must be developped. when the amount of users increase in the supply chain, processes and steps of systems will be more complex. There is an effective and usable method named as six sigma. This perspective aims to provide zero defect in the theory developping stages of supply chain. In the practical and implementation life, it is impossible because of changes, diversification in the life. This methodology has been chosen as a quality improvement technique to solve the problem in a production and supply chain system for industrial sector. By this way sustainability of Supply chains' and production processes can be provided and improved continuously. This study aims to present literature survey and overview about this quality method, six sigma and supply chain. This research includes some implementation stories, backgrounds of firms of services and industrial sectors. At the end of this study, it presents a case study of XB company and some suggestions can be offered about the case study according to the results.
\end{abstract}

Keywords: Quality oriented, six sigma, sustainability, supply chain, production

\section{INTRODUCTION}

Supply chain management (SCM) includes these important activities. These are sorted like this: delivering the right product to the right place, at the right time and at the right price is one of the most significant factors of business modification. Nowadays, it is one of the influential expense saving and profits sweetening strategies (Url1). According to the other definition, Supply chain management (SCM) is the process of planning, applying, and controlling the operations of the supply chain with the destination to resolve and supply customer requirements as expeditiously as possible. SCM comprehends the planning and management of all facilities including in sourcing, transition, and logistics management facilities (Url1; Url 2).

At the end stage of the continous of trends that started off from Business Process Reengineering, and Total Quality Management that have followed only the internal workings of an association, SCM purposes at combining the interval systems' structure of company to these of its suppliers, sharers and consumers (Erol and Ferrell, 2004). Technologies such as the Internet, transportation and software of warehouse management, programs of production and plant scheduling and also software that supports demand forecasting, SCM a adaptable strategy to acquire (Erol and Ferrell, 2004; Gunasekaran and Ngai, 2004).

The facilities in a supply chain regularly involve suppliers, customers, manufacturing-production centers, store houses, distribution locations and retail outlets (see figure 1). These facilities are interconnected via transportation and communicating relation on which raw materials, work-in process, inventory, end products, goods, and information flow stream structure. The supply chain comprises multiple business that occasion efficiently like a single firm with whole required information availability (Sheikh, 2003). 
Figure 1: Framework of Basic Supply Chain (Erol and Ferrell, 2004)

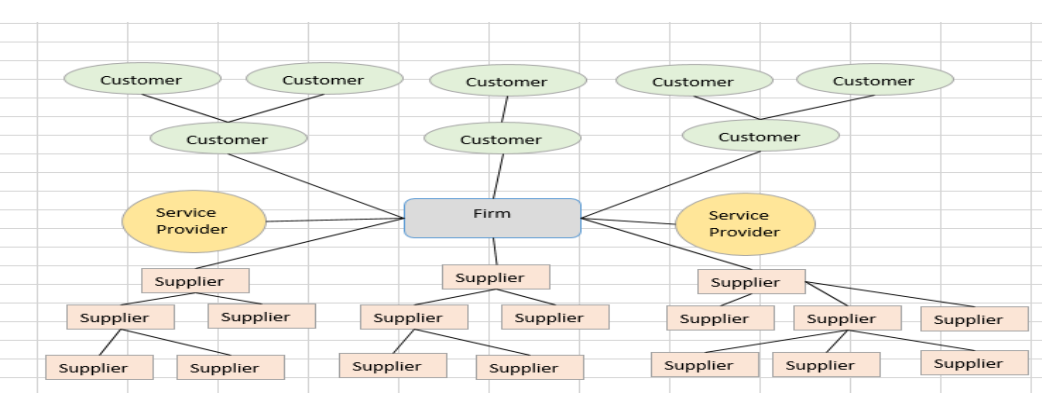

Generally, the focus of supply chains is on specific functionalities such as purchasing, manufacturing, and shipping to support logistics operations. Presently, the effective management of technology and quality is the key point to increased quality level and supported competitive situation in global environment. Supply chain quality is a key component in achieving competitive advantage. The combination of logistics functions into integrated supply chain systems has increased the requirement for improved process quality. Improving the quality of all supply chain processes results in decreased costs, improved resource utilization, and improved process efficiency (Wing et al., 2005). The competitive environment of the 21th century requires the delivery of expense, effectiveness, high service levels, high quality of products and services (Benita et al., 1998; Wing et al., 2005). Some research studies have examined how quality management can be applied in SCM to develop the execution of the whole supply chain network. The continuous improvement issues accomplished by Deming, Juran, Feigenbaum and Crosby have developped overview for the measurement of supply chain management. Lately, the Six-Sigma development methodology has become extremely significant and popular. A review of literature and survey present that Six-Sigma methodology has been applied in scopes as human resource functional components and supplier-customer improvement. Six-Sigma could be applied to improve a structural model for appraisal, developing and controlling quality level in the supply chain network. Development in the quality of processes and stages of all supply chain influences to the simultaneous reducing of expenses, costs and sweetening of service (Wang et al., 2004). Six sigma seeks to develop the quality of the output of a process by defining and removing the reasons of defects and minimizing variability in processing and business processes. It needs a set of quality management technics, mainly empirical, statistical technics, and occurs a special infrastructure of human within the organization who are specialists in these technics (Tennant, 2001; Url 3). For organizations to stay competitive, they must continously reduce costs via improved productivity. Six Sigma achieves this by focusing on the reduction of both defects and non-value added activities. Its importance has been increased recently and it has serious effects on a company's success (Tennant, 2001). Therefore, in this study, six sigma has been chosen as a quality improvement philosophy to solve the problems in production system of a pipe application. The research topic is about the application of six sigma in usage and re-machining processes of the pipe production. During the research, rolls used in tube machines were taken into account as the main subject. This report summarizes the work that is done during the research. In the first part, objectives and literature survey will be given about Six Sigma tools. Then the system and its problems will be examined. Define-Measure-Analyze-Improve-Control (DMAIC) methodology of Six Sigma will be followed step by step. Priorities of all problems will be defined, the goals and objectives will be specified. Then collected data about current processes for future comparison will be presented. Analysis will be made about collected data and problems. At last, suggestions will be offered about the new system and the research will be concluded. Objectives in this research are to understand the six sigma approach and its tools in detail with the help of the literature survey, then making a successful pilot study in a firm that Six Sigma culture by appliying these tools on the related research topic.

\section{LITERATURE REVIEW}

\subsection{General Background of Six Sigma}

To understand the concepts in Six Sigma better and to apply accurately, literature survey has been made from different kinds of sources. Six Sigma methodology, its history and steps were investigated. The results of the survey were presented.

\subsubsection{What is Six Sigma?}

Six Sigma (SS) allows comparison of products, of varying complexity on basis. Also, it provides a common basis for benchmarking (competitors and non-competitors). The higher the sigma level, the better your operation is performing (Url 3, see Figure 2).

A standard deviation is the square root of the average squared differences between a set of data points and their common average according to the higher the sigma level and the lower the number of detects. It is less important, however, to understand the mechanics of the calculation than it is to understand what it means for a process to be operating at a certain sigma level (Url 3). Six Sigma is a classified and systematic technique for development of strategic stages and service 
development which depends on statistical techniques and also the scientific method to support considerable deduction in defect ratio of consumer's voice. A significant stage in steps of Six Sigma development determines exactly what the consumer needs and specifies failures and defects in parts of requirements of customers critical to quality factors (Linderman et al., 2003; Url 2; Url 3).

Figure 2: Six Sigma Levels (Url 3)

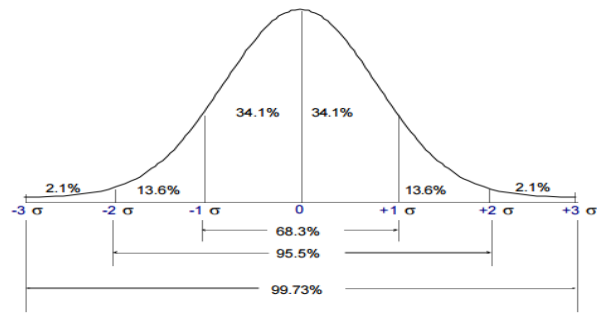

Use of these unique metrics provides to explain objectives and support them well-defined. However, sometimes main data may not obtain for the system approach, as often develops with a new product, which causes it difficult to provide specific targets. In the steps of process development, the method is formed after the plan, do, check, act (PDCA) cycle. One popular technique utilizes define, measure, analyze, improve and control (DMAIC) as the five steps for the process development. Design step for Six Sigma is applied for incremental product design (define, measure, analyze, design and verify). Data and objective measurement have vital effect at each stage of the technique. Six Sigma guidelines determine a combination of proper tools at each step of the method. This careful integrating of tools with the statistical methods is unsurpassed to Six Sigma (Linderman et al., 2003; Url 2; Url 3).

\subsection{Background of Six Sigma}

The Greek Letter Sigma $(\alpha)$ has been the universally accepted symbol for standard deviation. Standard deviation is a measure of variation or spread. The quality tools and techniques that were named "Six Sigma" in 1986 by Motorola are not new. Six sigma(SS) occurred by Motorola and popularized by General Electric defines to a technic and set of tools that utilize statistical analysis to evaluate and develop an organization's performance, implements, and systems with prime aim of defining and removing difference to development quality. They were developed over the past 50 or more years, through the work of quality experts such as Deming Juran and others (Raisinghani, 2005; Url 4). Apart from mathematical field, SS is a company-wide transformation that has helped them and brought them for few years already, the success according to employees of Motorola, General Electric, Honeywell, Bambardier, Black and Decker, ABB, Polaroid and many other companies. The companies listed above can be reffered to as the "six sigma companies". Many other organizations have adopted a SS approach, but these particular companies have rejected their success and have emphasized the part played by SS in the achievement of this success. None more so than General Electric, as its Annual Report for 1998 states very clearly:

“... we plunged into SS with a company-consuming vengeance just over three years ago. We have invested more than a billion dollars in the effort, and the financial returns have now entered the exponential phase more than three quarters of a billion dollars saving beyond our investment in 1998, with a billion and a half in sight for 1999." (Url 5). As a result, SS has adopted, in a small number of large companies, benefits that present high interest to managers and to shareholders. One of these common characteristics of SS is a widespread focus on processes and the existence of a company-wide language for describing the capability of processes. The expected outcomes of SS efforts are faster and more robust product development, more efficient and capable manufacturing processes, more confident overall business performance (Sanders and Hild, 2000; Url 6; Url 7). The fundamental objective of the six sigma methodology is the implementation of a measurement-based strategy that focuses on process improvement and variation reduction through the application of Six Sigma improvement studies. This is accomplished through the use of two six sigma sub-methodologies: DMAIC and DMADV (Url 8).

\section{DMADV: Define, Measure, Analyze, Design, Verify (for new product improvement)}

DMAIC: Define, Measure, Analyze, Improve, Control (for process improvement). The new approach to six sigma developed by Mikel Harry and Richard Schroeder (2000) and packaged them in the Define, Measure, Anlyze, Improve and Control (DMAIC) methodology. The DMAIC approach consists of management involvement, organizational structure to facilitate the improvement, customer focus, opportunity analysis, extensive training and reward and recognition for successful problem solving. Its benefits include the standardization of the methods, global adaption of the methodology (Gupta, 2004).

DMAIC has five phases including:

These phases are seperated into two groups as shown in Figure 3: 
Figure 3: Phases of DMAIC (Url 9)

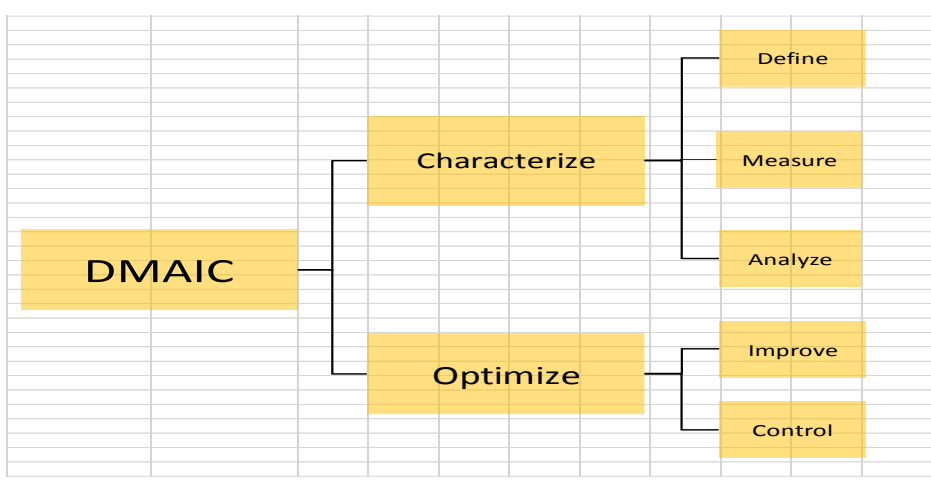

The six sigma companies are concerned with the reduction of variation and with the reduction of detective products and services. However, they often focus on "defects per million opportunities" (DPMO) or DPMO as metric and their performance standards are:

Table 1: DPMO Table ( XB Holding, Black belts Education Documents)

\begin{tabular}{|l|c|c|c|}
\hline SIGMA & DPMO & COPQ & CAPACITY \\
\hline 6 Sigma & 3,40 & $<10 \%$ of sales & World Class \\
\hline 5 Sigma & 230 & 10 to $15 \%$ of sales & \\
\hline 4 Sigma & 6.200 & 15 to $20 \%$ of sales & Average Industry \\
\hline 3 Sigma & 67.000 & 20 to $30 \%$ of sales & \\
\hline 2 Sigma & 31.000 & 30 to $40 \%$ of sales & Noncompetitive \\
\hline 1 Sigma & 700.000 & & \\
\hline
\end{tabular}

It is seen on Six Sigma Process Capability Chart above (in Table 1); as the sigma level increases, DPMO decreases, COPQ (Cost of poor quality) decreases and capability gets stronger.

\subsection{Relevant Tolls/Concepts:}

They are many tools and concepts used in Define phase as below:

-Project Charter -Brainstorming -Voice of the customer (VoC) - Pareto Analysis -Process mapping -SIPOC (Suppliers, Inputs, Process, Outputs, Customers) -IPO (Input, Porcess, Output)

\section{Business Porcess Mapping}

It helps to understand baseline better by using mapping techniques as below:

-Completing verifying and validating hgh-level (not 'should be' or 'could be') business porcess map.

-Completing SIPOC representation, describing the Suppliers, Inputs, Process, Outputs and Customers.

Customers: It requires to determine customers such that:

-Identifying customers and segmenting according to their different needs and requirements.

-Collecting data and displaying to better understand customer8s) critical needs and requirements.

Project Charter: The main items are business case, problem and goal statements, project scope, milestones, roles and responsibilities, project-research plan.

Opportunity Statement: The opportunity statement should adress these questions:

-What is wrong or not working? -When and where do the problems occur?

-What is the impact "pain" on our employees? -How extensive is the problem?

-What is the impact "pain" on our customers? -What is the impact "pain" on our business?

-Does it make strategic sense to adress this issue? 
The opportunity statement does not make assumptions that cannot be supported with data, that will not create value, contain or identify a solution. Six Sigma attempts to identify the root cause of the problem, artificially define the scope too narrowly or define the scope too broadly.

\subsection{The culture of Six Sigma}

A significant feature of six sigma culture is the existence of what could best be described as management by fact. The performance of the process at the start of the project is recorded in a run chart or a control chart. At the completion of the project, the improvement is clear. The charts prominently displayed alongside other diagrams and a clear explanation of what is being mesured and how the chosen improvement actions were arrived at. There is evidence of a readily accepted self-discipline in this style of communication, a discipline which often surprises visitors and alarms suppliers.

\subsubsection{Implementation of Six Sigma Strategies}

There are three general policies of six sigma improvement. They are six sigma engineering organization, six sigma organization and strategy selection for individuals and research areas.

Six sigma organization uses a methodology of training all individuals, in all scopes, in the fundamental concepts and tools included in the implementation of six sigma. Six sigma engineering organization strategy focuses on training and improvement within the design and manufacturing engineering departments of the business.

The third classification strategy selection refers to the development on strategically-selected employees (Sabders and Hild, 2000). As with other quality programs such as TQM, determining Six sigma varies between organizations. For some companies, applying six sigma methodology means solely using the specific problem-solving stages involved; others use one or more of the strategies (Ingle and Jacobs, 1999).

\subsubsection{Roles and Responsibilities:}

Many organizations fail to execute programs such as Six sigma because they attempt to implement too many of them. Six sigma requires strong executive sponsorship and support from functional leaders. Incentives must be created so that "Line Managers" consistently. Some of them are that

-devote adequate resources to research teams, seek out potentiall high effect research ideas. Leaders must be identified to become black belts and succession plans need to allow for the repatriation of these black belts into the business.

\subsection{The Requirements of Six Sigma}

Strong leadership and top management commitment

Good support from top management is imperative in the restructuring of the organisation and achieving the cultural change and motivation of employees towards quality and the Six Sigma strategy to the business.

\section{Cultural change}

Employees have to be motivated towards the introduction and development of Six Sigma program through various reward and recognition schemes. There can also be a problem of employees dismissing Six Sigma as the latest fad or hype. To overcome this problem and also to allay the fears that employees may have, there has to be early and effective communication to all employees on the why and how of Six Sigma.

Training

Training is a crucial factor in the successful introduction and development of Six Sigma program. It is important to communicate both the 'why' and 'how' of Six Sigma as early as possible and provide the opportunity to people to improve their comfort level through training classes. There is usually a hierarchy of expertise, which is identified by the belt system. Within $\mathrm{GE}$, the belt system is fundamentally divided into:

Campions: These are trained in the essentials of the six sigma methodology focusing on selecting the research that is aligned with business goals. Identify strategically important projects for the improvement teams and provide resources, typically receive an orientation to Six Sigma rather than detailed training, promoting and leading the Six Sigma deployment in significant or critical areas of the business Champions must select and mentior six sigma project leaders callled "Belts" and align and integrate the six sigma launch into their organization (Knowles et al., 2005)

Master Black Belt (MBB): This concept is often the key support person to the champions to assist in research defininition and the mentor and lecturer of six sigma green belts and six sigma black belts. It requires extensive research management experience according to the six sigma methodology and statistical tools. fully trained quality leaders responsible for Six 
Sigma strategy, training, mentoring, deployment and results generally serve as instructors and internal consultants. Black Belts (BBs) - Full-time Black Belts lead improvement projects and typically receive 4 weeks of training

Six Sigma Belts: A black belt should present team leadership, understand team dydnamics and assign team member roles and responsibilities. This belt has a thourough understanfding of all aspects of the DMAIC model in accordance with six sigma belts. Green belt analyzes and solves quality problems and is involved in quality improvement research scopes. Green Belts are part-time improvement specialists that receive less training since they provide supporting roles on the improvement projects. Yellow belt is typically employee and has a solid basic knowledge of the six sigma methodology. The work of these types reflects excellent understanding of a quality etc. profit relationship (Knowles et al., 2005; Url 11; Url 12; Hoerl, 2001).

\section{ADVANTAGES OF IMPLEMENTING SIX SIGMA METHODOLOGY}

\subsection{Manufacturing sector}

Six Sigma has been achieve used in different production companies such as General Electric, Boeing, DuPont, Toshiba, Seagate, Allied Signal, Kodak, Honeywell. For example, Motorola saved US\$2.2 billion in the first 5 years of adoption. Honeywell saved in excess of US\$2 billion since implementing Six-Sigma in 1994. General Electronics initiated Six-Sigma in 1996 and generated more than US\$2 billion of revenue in 1999. Black \& Decker's savings rose to approximately US\$75 million in 2000, which was more The original concept of six sigma than double the savings of the previous year, and accumulated over US\$110 million since 1997. For example, Motorola recovered US\$2.2 billion in the first 5 years of adoption. Honeywell saved in excess of US\$2 billion since applying Six-Sigma in 1994. General Electronics launched SixSigma in 1996 and emergent more than US\$2 billion of revenue in 1999. Black \& Decker's savings rose to nearly US\$75 million in 2000, which was more The original concept of six-sigma than double the savings of the previous year, and generated over US\$110 million since 1997 (Mayor, 2003; Wang et al.,2004).

\subsection{Financial Sector}

Typical six sigma projects in financial institutions contain developing accuracy of allocation of cash to decrease bank charges, automatic payments, developing accuracy of reporting, decreasing documentary credits defects, decreasing check collection defects, and decreasing difference in collector performance Bank of America reported as developping in customer satisfaction and reducing in customer problems after applying six sigma

\subsection{Healthcare Sector}

Six sigma fundamentals and the healthcare sector are very convenient because of the healthcare system of zero tolerance for failures and potential for decreasing medical defects and issues. Some of the successfully implementations of six sigma studies involve developping timely and accurate requirements, following the process of healthcare distribution, and decreasing the inventory of operative equipment and interconnected costs.

\subsection{Engineering and Construction Sector}

In 2002, Bechtel Corporation, one of the largest engineering and construction companies in the world, provides savings a huge amount with an investment in its six sigma program to determine and obstruct failures and defects in engineering and construction industries from design to manufacturing, production, construction to on-time delivery of payroll of staff member (Knowles et al., 2005; Mayor, 2003; Wang et al.,2004).

In Six Sigma, the important point is on process development in order to increase capability and decrease variation of process. Six Sigma methodology is about solving problems. The main isue is on business problems that causes harmful effects and extra costs to the companies (Oudrhiri and Pellizzetti, 2006). It is not a classification of best applications or methods. Every corporation is different and thus failures and extra expense etc. are the problems they face. Six Sigma refuses pre-defined solutions and determines and analyses problems to the degree of their root causes (Russ et al., 2008). Six Sigma is generally applied in organizations by determining Six Sigma projects. Six Sigma tools are used in implementing Six Sigma research. Some of the Six Sigma tools can be listed as; descriptive statistics, run chart, control chart, probability plot, check sheets, pareto chart, brainstorming, affinity diagram, interrelationship diagram, matrix diagram and prioritization matrices, quality function deployment, single factor analysis of variance, design of experiments and etc. (Rick and Michael, 2002; Siviy et al., 2007). The CMMI's (Capability Maturity Model Integration) process infrastructure offers a foundation for Six Sigma efforts and helps engineering processes of a business relate to its business processes. Moreover, Six Sigma is not a competitor to CMMI or other process fundamental structures and standards.

Integrating CMMI and Six Sigma can be in several ways as given below (Russ et al., 2008).

- Implement CMMI process areas as Six Sigma research ans studies. 
- Use Six Sigma as the tactical engine for high capability and high maturity.

- Apply Six Sigma to improve or optimize development strategy of an organization and

steps of processes.

- Integrate CMMI, Six Sigma, and all other development initiatives to support a standard for

the execution of every study throughout its life cycle.

\section{SIX SIGMA IMPROVEMENT TECHNOLOGY IN THE SUPPLY CHAIN NETWORK}

A risk management strategy need to objective to occur and continue a supply chain that is both resistant and elastic. An elastic supply chain can reply to unimagined sudden input differences. Accomplishment resistant and elastic supply chain will turn on the degree of visibility and control over operations as well as the timely availability of spare operation capacity. A main first stage toward successing this is to take critical path operations under control. Though controlling processes' outputs by control as it was in traditional quality management is not a satisfactory way because of non-conforming factors would 'slip through the net' and, in any case, control is 'after the case'. So processes must be under control before it applied outputs.

Globalisation, change of marketing, outsourcing efficiency supply chains to be more complicated factors. Thus they are developing sensitive to risk of distribution. Because supply chains contain the linked operations of the different entities in a network, it is applicable to follow the methods in which operation risk can be directed. Despite they divide a number of properties such as unchanging processes, having monitoring control over output difference and low inventory levels, the key variation between the two is their skill to respond to differences in input. The integration of six-sigma and SCM follows from the fact that both have been lustily selected as "operation approach". With the six sigma essent basically being a operaation oriented approach, a six sigma metric actualy measures how well the underlying operation is performing. This "operation approach" is also a property of supply chain management. Six sigma is a data driven, continuous improvement technics that look for take operations under control and improve operation capability. In one Six sigma project, Ford analyst measured inventory levels at one of their plants during manufacturing time and followed that levels changed by $20 \%$ over monte. With further research they found one of the significant causes of invnetory fluctuation was inefficient and inconsistent unloading of parts at the plant docks Following stages to develop dock utilisation and in this way driving out operation led to annual savings of more than $\$ 3.7$ million due to inventory reduction, decreased overtime for unplanned materials handling and other savings (Christopher and Rutherford, 2004).

\subsection{Applying Six-Sigma to Supplier Development}

Supplier development involves a long-term cooperative effort between a buying firm (e.g. a manufacturer) and its suppliers (i.e. its material providers), and is aimed at creating and maintaining a network of competent suppliers. The development activities include supplier selection and monitoring, supplier assistance and training, the provision of incentives for continuous improvements, and supplier organizational integration. The ultimate objectives of supplier development are supplier base reduction, concurrent engineering, reductions in cycle time, reductions in inventories, and increases in customer satisfaction. There should have five steps in the supplier certification process: preliminary evaluation, product design and quality certification, a review of the supply process, performance monitoring, and certification. Raytheon Corporation has applied Six-Sigma to improving its supplier development activities (Breyfogle, 1999).

Six sigma offers more robust supply chain processes. Accross unpredictable events supply chain processes need to be agile and responsive. To accomplish this problem there must be spare process capacity where it is needed most along the critical path (Url 13; Wang et al., 2004).

The key is to approach supply chain activities as processes. Supply chain processes can be improved untill the six sigma level. The framework consists of five integrated modules. These are Define, Measure, Analyse, Improve, and Control steps. The basic framework of the Six-Sigma improvement technology in the supply chain network is given in Figure 4.

Figure 4: The framework of the Six-Sigma model in the supply chain (F. K. Wang et al., 2002)

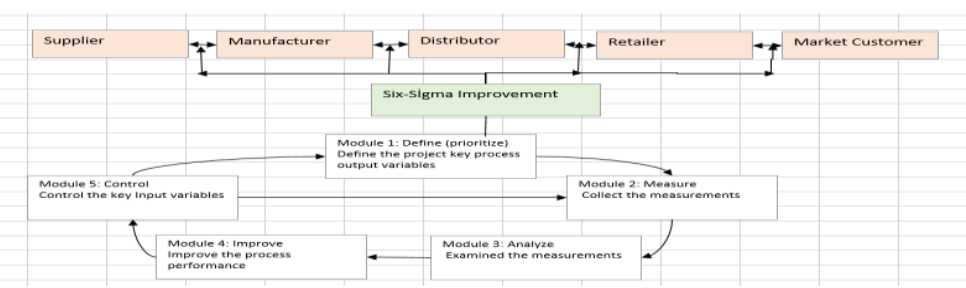




\section{WORK STREAM MAPPING IN PIPE PRODUCTION}

The raw materials of pipes reach $X$ Company as steel bands (strip) from the suppliers. All strip passes through an in-line strip wash process which removes oil, dirt and smut from the strip. The strip wash process is essential in meeting with customer and industry requirements. The cleaning process includes a wash tank, rinse tank and strip dryer. These bands are turned into pipes by using rolls. This process forms the strip into a tabular shape. The rolls used in pipe forming process are forming, blade's welding and sizing rolls respectively. First of all, steel bands enter into farming rolls and they are bended. Then they are transferred to blade rolls to get a more bended shape almost approximate to the final shape. After that, they pass through the welding rolls which weld the tube by means of high frequency induction welding and two ends of the tube combine. At last, they go into sizing rolls and attain their last shape. Pipes pass through scarfing process next. Scarfing is the process in which the outside weld bead is removes form the pipe. The necessity of this process is to insure a smooth outer surface of the pipe. At the end of this process, the production is completed. After each production, samples are taken from each pipe batch and they are tested (outside diameter, wall thickness, rockwell, eddy current). Finally, pipelines are packaged and sent to the customer.

\section{Goal Statement:}

Define the objective of the research, $Y=f(x)$ and is specific, measurable, attainable relevant and time-bound. Benefits may include: improved response time, lower lead time, reduced warranty claims, improved reliability, lower operating costs. The goal statement should adress these questions:

What is the improvement team seeking to accomplish? How will the improvement team's success be measured? What specific parameters will be mesured, what are the tangible results deliverables (ex. reduce cost, cycle time, etc.)? What are the intangible deliverables/results?

\subsection{Layout Optimization for Pipe Production in Factory}

The goal is to optimize the factory layout which enables appliers to eliminate non value added activities and thus decrease the unit production cost $(Y)$ to $65 \$ /$ ton. This involves costs of coil slitting $(x 1)$, welding lines $(x 2)$, LS finishing lines (X3), packing lines (x4). Amortisation expenses of the investments suggested by this research cannot exceed $0.72 \$ /$ ton. Therefore, estimated Level 1 benefit out of this research is:

75.000 (tons/year) * (37.66-30-0.72) (\$/ton) * $0.7=364.350 \$ /$ year."

The research scope defines the boundaries of the business opportunity. The goal statement should adress these questions:

-What are the boundaries, the starting and ending steps of a process, of the initiative?

-This is necessary to maintain "boundaries" for the team to remain focused.

-What parts of the business are included?

-What parts of the business are not included?

-What, if anything, is outside the boundaries of the team?

An example can be given for research scope to realize it as given below (XB Holding,2002).

Layout Optimization for Pipe Production in Z Factory (BMB)

Start Boundary: Taking the steel coil into pipe production

End Boundary: Transporting the packed pipes to customer or stock

In Scope: Slitting line

All back pipe and rectangular hollow section units within the welding hall. All back pipe and rectangular hollow steps of finishing lines.

Out of Scope: Layout change for galvanishing line. Layout change for annealing furnace"

This plan identifies the milestones necessary to achieve the objectives and the schedule for completion. A major component of the research plan is an action plan that displays activities, responsibilities and dates by milestone and task.

\subsection{General Problems in Production Procedure}

As a result of the discussions with the black belt three main problems were determined. These are idle times, reduction in speed and customer complaints about surface defects. According to the customer complaints, much more meter pipe from 
amount of production had surface defects. 215.256-meter length pipes were scraped, taken back. This was caused financial loss. Approximately, 178.396 meter pipes were reproduced. A huge amount compensation was paid. The frequency percentages of Idle time reasons in a year are presented as below in Table 2.

\section{Table 2: Frequency Percentages of Idle Time Reasons in a Year}

\begin{tabular}{|l|r|}
\hline Reasons of Idle Time & \multicolumn{1}{|c|}{$\%$} \\
\hline profile block changing & 38,6 \\
\hline complete roll changing & 16,3 \\
\hline surface fault adjustment & 6,7 \\
\hline acumulation mix & 10,5 \\
\hline upper burr toll changing & 2,6 \\
\hline roll wear waiting & 5,2 \\
\hline dmeter adjustment & 2,2 \\
\hline welding adjustment & 3,6 \\
\hline empeder change & 5,8 \\
\hline accumulation on saw & 2,4 \\
\hline personel requirements & 6,2 \\
\hline & \\
\hline
\end{tabular}

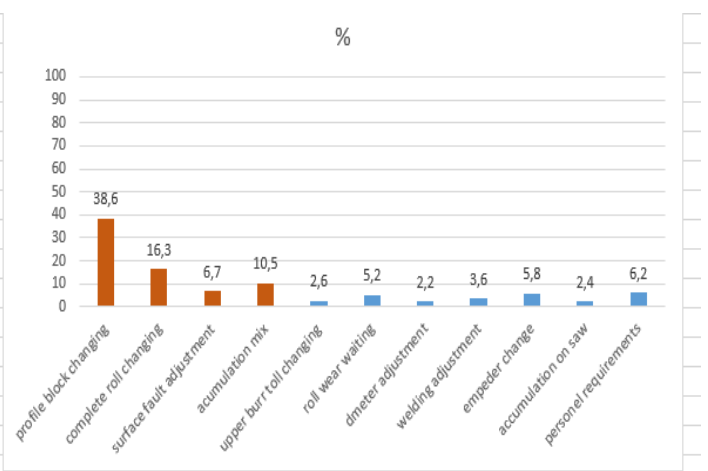

About data of Idle times, at the same tiem data about idle times related to the rolls were sorted from all idle time reasons. Idle times related to the rolls are profile block changing, round pipe diameter adjustments, surface defect adjustments, roll amortization etc. By collecting thse types of data, it was aimed to find the most significant reasons of times related to the rolls. The steps of production system were presented in table aa. This table was classified to determine the inputs, processes and outputs of the structure of system. This technique is usable tool to research the capabilities of the system at the starting stage of the study. Setup instructions, operator, roll sets and roll usage plan are components of Input stage. Machine matching, setup, re-maching, roll changing are components of Process stage. Customer complaints, scraps, speed and idle times are components of output stage. This IPO (input-process-output) Table 3 is shown as below.

Table 3: Phases of System Table

\begin{tabular}{|l|l|l|}
\hline Input & Process & Output \\
\hline Setup instructions & Machine matching & Customer complaints \\
\hline Operator & Setup & Scraps \\
\hline Roll sets & Re-maching & Speed \\
\hline Roll usage plan & Roll changing & Idle times \\
\hline
\end{tabular}

\subsection{Components of System - SIPOC Table}

All relevant components of the research should be identified before work begins so the whole system can be understood clearly. Hence, a SIPOC table was organized to answer these questions:

Who are the consumers of the process, what are the requirements of the consumers, and what specifications are placed on the Inputs? When the study does not deal with the real customers or suppliers, machines and warehouse could be thought as these components (see Table 4).

Table 4: Supplier-Customer Framework

\begin{tabular}{|c|c|c|c|c|c|}
\hline & $\mathbf{s}$ & I & $\mathbf{P}$ & $\mathbf{O}$ & C \\
\hline & Supplier & Input & Process & Output & Customer \\
\hline \multirow{2}{*}{$\begin{array}{l}\text { Roll } \\
\text { remaching } \\
\text { process }\end{array}$} & roll warehouse & $\begin{array}{l}\text { Roll used } \\
\text { in production }\end{array}$ & roll remaching & $\begin{array}{l}\text { roll sets which have } \\
\text { reduced diameters by } \\
\text { remaching in CNC }\end{array}$ & pipe machines \\
\hline & roll warehouse & $\begin{array}{l}\text { Roll used } \\
\text { in production }\end{array}$ & roll remaching & $\begin{array}{l}\text { roll sets which have } \\
\text { polished surfacess by } \\
\text { remaching in turn benches }\end{array}$ & pipe machines \\
\hline \multirow{2}{*}{$\begin{array}{l}\text { Roll Usage } \\
\text { Process }\end{array}$} & roll warehouse & rolls ready to use & roll change & $\begin{array}{l}\text { machines ready for } \\
\text { production }\end{array}$ & tube machines \\
\hline & tube machines & setup instructions & roll setups & rolls used in production & roll warehouse \\
\hline
\end{tabular}

\section{PARETO ANALYSIS}

A pareto chart can be constructed by segmenting the range of the data into groups. The left-side vertical axis of the pareto chart is labeled frequency- the number of counts for each category, the right-side vertical axis of the pareto chart is labeled with the group names of your response variables (Akın, 1996; Akın and Ozturk, 2005; Url 8). The number of data points is determined by residing within each group and construct the pareto chart, but unlike the bar chart, the pareto chart is ordered in descending frequency magnitude and users define the groups.

Vilfredo Pareto was a 19th century Italian economist and his researches were about economic problems using mathematics and the technique was named with his name and this method supports to determine and group the detects-error due to percentage importance. He specified that 80 percent of the location in Italy was belonged by 20 percent of the citizens. 
This method is a method of analyzing causes of problems to support an effective solution.Generally, this way implements according to 80/20 law. Pareto diagrams are the graphical tool applied in Pareto analysis Pareto analysis is a method which is applied to distinguish reasons from less important ones (Gitlow et al., 2005; Cravaner et al., 1993; Leavengood and Reeb, 2002).

\subsection{Analysis for Idle Time Production}

Data was collected in measure phase about the idle time reasons of the rolls. In Anlyze phase, pareto diagram is used to see the reasons that affect the idle time most. This diagram can be presented in Figure 5 .

\section{Figure 5: Pareto Analysis}

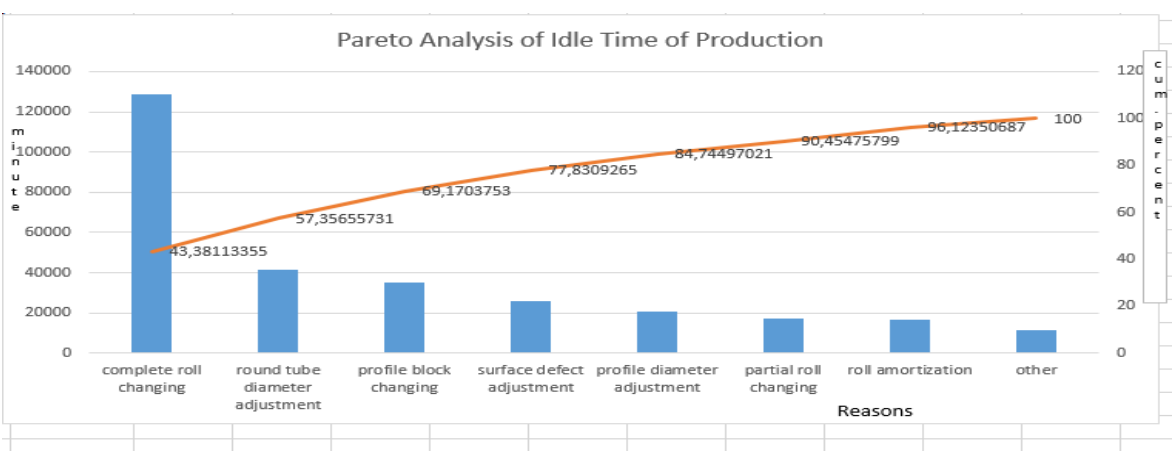

Considering pareto Diagram ( see figure 5) ; average changing times have been computes and features were arrayed from top to bottom. complete roll changing, round tube diameter adjustment, and profile block changing took the biggest percentage. To see all of the changes, surface detect adjustment has also been examined through the analysis. These four reasons have high risks features. Firstly, These foru reasons must be eliminated from the systems according to the Pareto analysis.

\section{GENERAL OVERVIEW OF SIX SIGMA APPLICATION-CASE STUDY IN MANUFACTURING FIRM}

The main is to resign Six Sigma quality product or service without suffering from a poor understanding of customer necessaries and resign performance of the suppliers. To release Six Sigma in a supply chain network, management must clearly define potential effects of the enterprise on corporate performance and supply chain groups (Montgomery, 2008). To better know customer necessaries, companies use to keep in mind that errors are decreased if they focus on bring customer necessaries to the Six Sigma level Bob,Galvin, former CEO of M, asked IBM, which is a big firm, to apply Six Sigma Suppliers must also find value in collaborating with the organizatör. One method to detect value to the suppliers is to provide a strategy to occur relationship with the suppliers who commit to apply Six Sigma attempt and aline with the corporate objectives, and decrease the number of suppliers who aren't enthuastic about having great advancement in a short period of time. To release the enterprise, managers must present a commitment document, mutual performance aims, commitment to eductation and progress review schedule (Antony and Banuelas, 2002; Wang, et al.,2004). Since the early 90s, companies have been researching on decreasing number of suppliers. As the companies developed their design and processing processes, dependency on development by supplier developed to success continually demanding business aims Similarly, when applying Six Sigma, M Company asked its suppliers to aply its Six Sigma travel. To obtain the suppliers enthusiastic, quite a few activities were handed to training suppliers for the dramatic development and the objectives it suggested them. After winning the Malcolm Baldridge National Quality Award, M Company felt privileged to distributed its achieve story with its suppliers and customers. Regular supplier informations were held to communicate the $M$ process, its suppliers' expectation and stable sources. To some point, suppliers were stabled to participate in M's Six Sigma process to provide continually developing products and services. To development suppliers' understanding of the Six Sigma process, they were used to share four main factors, which were as follows (Montgomery, 2008; Antony and Banuelas, 2002):

Understanding Six Sigma-An overview of the Six Sigma methodology and terminology.

Process Quality Improvement-An overview of process improvement methods explaining applicability of various tools.

Design for Manufacturability-The process of integrating product and process development for producing defect-free products.

Cycle Time Reduction-Straightening out material flows to practice lean principles. 
M University was then established to institutionalize corporate strategies and manage the variable process. It suggested services to uplift M Company's suppliers' capabilities and strengthen the relationship with them. The university also had a consulting group to provide its clients in applying different methods. Moreover training and guiding suppliers, following policy of M Company was varied and procedures were altered to image the expectations of its suppliers of M Company. The new procedures imaged intent and verification to minimize product research and verification facilities, and promote process control and development facilities. Supplier' scorecard would be followed periodically difference success and defining areas for development. Furthermore buying policies, a process for suppliers involvement in theproduct improvement step was applied This allowed $\mathrm{M}$ to leverage its suppliers' speciality and sources and conspire with its suppliers in increasing new products This early inclusion of suppliers supplied $M$ engineers to produce designs that its suppliers could manufacture at low fault rates (Antony and Banuelas, 2002; Wang, et al.,2004). Application Six Sigma is supply chain needs a strategic thinking, proper planning and significant commitment to optimize the performance of the supplier group. Besides, including customers allows an organization to specify products trhat are acceptable to customers and spplied by suppliers for preservation the product surplus. There are different companies, such as $\mathrm{C}$, that have included their suppliers in the Six sigma interference to provide regular commitment to the institutional performance development. Six sigma in the supply chain is serious to success higher sigma levels. If a company is application Six sigma, it can't be researching with three-or four sigma suppliers or customers with unrealistic expectations, and hope to success its Six Sigma quality objectives (Nonthaleerak and Hendry, 2006).

\section{CONCLUSION}

By the help of this research, it is aimed to develop knowledge about six sigma quality system and its tools. Six sigma method is investigated to develop the processes of supply chainSix sigma method requires to be applied forever in a supply chain because of it is a sustainable research area. It is impossible to provide zero failure, defect in real life but it is a continuous process. Firstly, A deep literature survey has been accomplished to understand the concept better. For the case study, the present system was examined and the research scope was specified by considering the operations that needs development. The applications of six sigma methodology to the supply chains was presented. Six sigma methodology was applied to define the importance of quality and satisfaction of customers in the supply chain management and production area. The probable problems of the system were observed and main causes of problems were discovered to eliminate them or reduce the effects of these problem in the systems. The phase of analyses provided to understand which items of problems causes the failures and defects. The research can be extended with other problems and factors of system according to the discovering from aspects of quality. Today, supply chains management includes more and more complex structures because of their inconsistent objectives. Conducting comlex structures are very hard so this frame needs to be developed.

\section{REFERENCES}

Akın, B. , 1996. “ISO 9000 Uygulamasında İşletmelerde İstatistik Proses Kontrol Teknikleri”, Istanbul: Bilim Teknik Yayınevi, pp. 49-50.

Akın, B., Ozturk, E., 2005. Istatistiksel Proses Kontrol Tekniklerinin Bilgisayar Ortamında Uygulanması, VII.Ulusal Ekonometri ve İstatistik Sempozyumu Bildiriler CD, Istanbul, pp.1-15.

Antony, J., Banuelas, R. 2002, "Key ingredients for the effective implementation of Six Sigma program", Measuring Business Excellence, vol.6, no. 4, ABI/INFORM Global, p.20

Benita M. Beamon, B.M., Tonja M. Ware, T.M. 1998, " A process quality model for the analysis, improvement and control of supply chain systems", International Journal of Physical Distribution \& Logistics Management, Vol. 28 No. 9/10, pp. 704-715.

Breyfogle, F.W. 1999, Implementing Six Sigma: Smarter Solutions Using Statistical Methods, John Wiley: New York.

Christopher, M. ,Rutherford, C. (2004) “Creating supply chain resilience through agile six sigma”,CriticalEye, June- August 2004, pp.24-28

http://www.valuenetworkmanagementforum.org/vnmf/images/past_events/competitive/publications/Creating_Supply_Chain_Resilience _Through_Agile_Six_Sigma.pdf)

Cravener, T.L., Roush, W.B., Jordan, H., 1993."Pareto Assessment of Quality Control in Poultry Processing Plants", Applied Poultry Science, 2, pp.297-302.

Erol, E., Ferrell, Jr. GW. 2004, “A methodology to support decision making across the supply chain of an industrial distributor a Department of Business Administration", Int. J. Production Economics 89 (2004), pp. 119-129

Gitlow, H.S., Openheim, A.J., Oppenheim, R.,Levine, D.M. (2005).”Quality Management “, Third Edition, McGrawHill, USA, pp. $366-367$. 
Gunasekaran, A. , Ngai, E.W.T. 2004, "Information systems in supply chain integration and management", European Journal of Operational Research 159 (2004), pp. 269-295.

Gupta, P. 2004 “Six Sigma Business Scorecard, Creating a Comprehensive Corporate Performance Measurement System”, The McGraw-Hill Companies.

Halseth, K. 2008 , "Process Modelling \& Mapping: The Basics, Regional Coordinator", Forms Management \& Production, David Thompson Health Region, Session 64, http://c.ymcdn.com/sites/www.bfma.org/resource/resmgr/articles/08_64.pdf.

Hoerl, R.W. 2001," Six Sigma Black Belts: What do they need to know?”, J. Quality Technology, vol. 33 no.4, pp 391-401.

Ingle, S., Jacobs, D. 1999, "Approaches to TQÖ adoption in an Irish context", Ho,S.K.M., TQM and Innovation, Hong Kong Baptist University, Hong Kong.

Knowles, G., whicker, L., Femat, J.H. and Canales, F.D.C. 2005, "A conceptual model for the application of Six Sigma methodologies to supply chain improvement", International Journal of Logistics: Research and Applications Vol. 8, No. 1, March, pp. 51-65.

Leavengood,S. and Reeb,J.,2002. "Part 3:Pareto Analysis and Check Sheets, Performance excellence in the wood products industry" Statistical Process Control, EM8771, January 2002.

Linderman, K., Schroeder, R.G., Zaheer, S., Choo, A.S. 2003, " Six Sigma: a goal-theoretic perspective", Journal of Operations Management 21, pp.193-203.

Mayor, T.2003, "Six Sigma comes to IT: targeting perfection", CIO Magazine, www.cio.com/archive (accessed 24 January 2004).

Montgomery, D.C., William H. Woodall, W.H. 2008, An Overview of Six Sigma, International Statistical Review vol.76, no.3,pp.329-346

Nonthaleerak, P., Hendry, L.C. 2006, "Six Sigma: Literature review and key future research areas". Int. J. Six Sigma Competitive Advantage, 2(2), pp.105-161.

Oudrhiri, R., Pellizzetti, F. 2006, “Using maturity models for Six Sigma and strategy execution”, IQPC 7, Annual conference, Amsterdam.

Radouane, O., Fabrizio, P. 2010,"Design for Six Sigma (DFSS): a cultural and paradigm shift from Deterministic to Probabilistic Design”, SEPG Europe, Portugal.

Raisinghani, M.S. 2005,"Six Sigma: concepts, tools, and applications" , Industrial Management \& Data Systems Vol. 105 No. 4, pp. 491-505, Emerald Group Publishing Limited.

Rick, H., Michael, S. 2002,"Optimize Your Solution: Integrating Six Sigma and CMM/CMMI-Based Process Improvement", 2.Software Technology Conference, 2002.

Russ, R., DanaSperling, D., Rometsch, R., PeterLouis, P. 2008,"Applying Six Sigma in the Field of Software Engineering", Lecture Notes in Computer Science, vol. 5338, Springer.

Sabders, D., Hild, C. 2000 , “A discusiion of strategies for Six Sigma implementation”, Quality Engineering (12)3, pp.303-9.

Siviy, J.M., Penn,M.L, Stoddard, R.W.2007,"CMMI \& Six Sigma: Partners in Process Improvement", Addison-Wesley.

Sheikh, K. 2003, "Manufacturing resource planning (MRP II) with introduction to ERP, SCM and CRM", McGraw-Hill, New York, pp.538-539

Tennant, G. T. 2001, "Six sigma: spc and tqm in manufacturing and services", The Evolution of Six Sigma, . Gower Publishing, Ltd. p. 6. ISBN 0-566-08374-4. Retrieved 2012-03-19.

Wang, F.-K., Du,T.C., Eldon, Y. L. 2004, "Applying Six-Sigma to Supplier Development", Total Quality Management, Vol. 15, No. 9-10, pp. 1217-1229. http://iceb.nccu.edu.tw/proceedings/APDSI/2002/papers/paper90.pdf

Wing, C.L., Chowb, S., Maduc, C.N., Kueic, C.-H., Yua, P.P. 2005, "A structural equation model of supply chain quality management and organizational performance", Int. J. Production Economics, vol. 96, issue 3, pp. 355-365.

XB Holding, Green Belts Education Documents, 2002

Url 1- Supply Chain Management, Rai Technology University Engineering Minds-Chapter 1, pp.3-11 http://164.100.133.129:81/eCONTENT/Uploads/Supply_Chain_Management.pdf, access time: 12.04.2017

Url 2- What is Supply Chain Management?, Penn State University, Smeal College of Business, https://www.smeal.psu.edu/cscr/pitch/whatis-supply-chain-management, access time: 12.04.2017

Url 3- Six Sigma, http://leansixsigmadefinition.com/glossary/six-sigma/ , http://www.cqeweb.com/chapters/chapter4.pdf, p.12

Url 4- The History of Six Sigma, http://www.tbmcg.co.uk/about-tbm/six-sigma.html

Url 5- Sinikov, C. 2002, “The Six Sigma phenomenaold or new perception of quality?”, www.alunet.com

Url 6- Six Sigma Vs. Quality Methodology, Jean Scheid, http://www.brighthubpm.com/six-sigma/34733-six-sigma-vs-quality-methodology/ Url 7- Six Sigma, http://www.brighthubpm.com/six-sigma/p3.html 
Url 8-Six Sigma Methodologies, http://www.6sigmastudy.com/Six-Sigma-Methodologies.asp

Url 9- How to Calculate Your DMAIC Process Sigma, http://www.brighthubpm.com/six-sigma/42956-how-to-calculate-your-dmaic-processsigma/

Url10-Mary K. Pratt-posted by Margaret Rouse, Business process mapping, October 2016. http://searchcio.techtarget.com/definition/process-mapping.

Url 11- How to Become Certified as a Six Sigma Green Belt or Black Belt, http://www.brighthubpm.com/six-sigma/27993-how-to-becomecertified-as-a-six-sigma-green-belt-or-black-belt/ Heidi Wiesenfelder, edited by Michele McDonough.

Url 12-Six Sigma Green Belt , https://www.isixsigma.com/events/six-sigma-green-belt-390/

Url 13- Six Sigma in Supply Chain Management, written by Suvo; edited by Marlene Gundlach, http://www.brighthubpm.com/sixsigma/43061-six-sigma-in-supply-chain-management 